\title{
Hospital Staff Shortage: the Role of the Competitiveness of Pay of Different Groups of Nursing Staff on Staff Shortage.
}

Combes, Jean-Baptiste ${ }^{1}$

1 Univ Rennes, EHESP, CNRS, ARENES - UMR 6051, F-35000 Rennes, France. Jean-

baptiste.combes@ehesp.fr

Orcid : 0000-0001-6594-8458

Lecturer in Health Economics at the School of Public Health

15, Avenue du Professeur Léon-Bernard - CS 74312

35043 Rennes cedex

FRANCE

0033 (0)2 99022718 - 0033 (0)6 86354606

Elliott, Robert Francis ${ }^{2}$

Skåtun, Diane $e^{2}$

2 Health Economics Research Unit, University of Aberdeen, Aberdeen, Scotland 


\title{
Hospital Staff Shortage: the Role of the Competitiveness of Pay of Different Groups of Nursing Staff on Staff Shortage.
}

\author{
Shortages of nursing staff in OECD countries have been a preoccupation for \\ policy makers. Shortages of staff may be the consequence of uncompetitive pay. \\ In the private sector, employers in different regions can offer different pay rates \\ to reflect local amenities and cost of living. Hospitals in the UK however cannot \\ set the pay for their employees, and as a result they might therefore incur staff \\ shortages. Moreover, occupational groups do not operate in isolation. Shortages \\ of staff may also be the consequence of the competitiveness of pay of an \\ alternative group of staff. This is investigated using two distinct groups of \\ nursing staff: assistant nurses and registered nurses working in English hospitals \\ in 2003-5 using national-level data-sets. We find that an increase by $10 \%$ of the \\ pay competitiveness of registered nurses decreases the shortage of both the \\ registered nurses and of assistant nurses by $0.6 \%$ and $0.4 \%$ respectively.
}

Keywords: Wage regulation ; Local pay; Standardised spatial wage differentials; Shortage of staff; nurses; pay competitiveness; labour substitution;

Subject classification codes I18, J31, I11,

This work was supported by the Medical Research Council under grant number G0800113-2.

\section{Introduction}

Shortage of nursing staff in OECD countries is a key policy issue. This paper shows that where the competitiveness of pay increases, shortage of nursing staff is reduced. In particular we consider the interaction of pay competitiveness between two groups of nurses. Previous literature in this area has considered single occupations in isolation. However, the health service is characterised by different occupations working as members of a larger team. Where the pay competitiveness of one group has an impact 
on their own shortage, it may also impact on another group in the presence of underlying links between the two. We examine this using two distinct staff groups within nursing: registered nurses (RN) who are qualified to a degree level and licensed to practice as such under the UK nurse regulatory authority and assistant nurses (AN) who have no formal nursing qualification and operate out-with the regulatory authority.

This extends the literature which has already established the link between the local competitiveness of pay of registered nurses with local variations in vacancy rates (Elliott et al. 2007; Elliott et al. 2010). We show in this paper that there is no evidence that hospitals have difficulties in hiring assistant nurses because of their own pay competitiveness but an increase of $10 \%$ of registered nurse pay competitiveness reduces the assistant nurse vacancy rates by $0.4 \%$ and registered nurse vacancy rates by $0.6 \%$. Where pay for registered nurses is uncompetitive, assistant nurses might foresee higher workloads in the current post or uncompetitive pay in potential future roles if they were to move up the career path to become registered nurses. Either way this would work as deterrent.

\section{Pay competitiveness}

Pay in the private sector is expected to differ between geographical areas within the UK due to differences in gender, age, education, industrial and occupational composition of the workforce. Higher pay in some areas of the country is also expected where the cost of living is higher while higher pay is also necessary to compensate for less pleasant working environments or amenities (Smith 1776; Rosen 1986). It is this latter form of geographical variation in pay that captures the competitiveness of pay through its ability to adjust to local labour market conditions. In the U.K. we expect this to feature within the private sector where only a small proportion of staff have their pay set by collective 
bargaining and an even lower proportion have their pay set nationwide (Metcalf, Hansen, and Charlwood 2001). Thus pay in the private sector is free to adjust to reflect local labour market conditions.

Pay in the public sector in the U.K. is set nationally by quasi arbitration bodies. Pay set in this way or by collective bargaining is less likely to vary locally (Traxler and Brandl 2011). In the U.K., where the healthcare sector is dominated by public sector provision within a National Health Service (NHS), nurses pay is set nationally by the NHS Pay Review Body. Therefore, pay offered by hospitals will not adjust to the local cost of living or working environment conditions (Elliott et al. 2007). Where local pay is not able to reflect local labour market conditions, hospitals will have difficulties in attracting staff.

The methodology in our paper follows that as outlined by Elliott et al (2006, 2010). Using the private sector as a benchmark, we extract out the pure spatial element of wage variation by standardising for other elements known to affect pay. This generates a standardised spatial wage differential (SSWD). Thus assuming the private sector represents the equilibrium in the local labour market: it is the standardised pay that is required to attract an employee to this geographical area. Given the national wage structure within the public sector, we expect less variation in standardised wage differentials within the public sector. By comparing the patterns in SSWDs between the private and public sector, we can construct a measure of the local pay competitiveness of the public sector: the public-private pay gap.

We identify appropriate private sector comparators for both assistant and registered nurses using the Standard Occupational Classification (SOC) system, where individuals are classified according to employment characteristics (see Office National Statistics). 
We use SOC groups representing “personal services occupations”, and “associate professional and technical occupations” as the private sector comparators for assistant and registered nurses respectively. The competitiveness of pay of assistant and registered nurses in any area can therefore be defined as the gap between their SSWD and that of their comparator within the private sector:

$\operatorname{gap}^{S}=\mathrm{SSWD}_{\text {PUBLIC }}^{S}-\operatorname{PriSSWD}_{\text {PRIVATE }}^{c}$

where $\mathrm{s}=(\mathrm{AN}, \mathrm{RN})$ and $\mathrm{c}=(\mathrm{SOC} 6, \mathrm{SOC} 3)$

These two public-private pay gap measures for assistant and registered nurses are then used to consider the effect of pay competitiveness on both their own shortages but also to test for interactions of pay competitiveness on the measure of shortage of the other.

\section{Data}

Our empirical analysis utilises data from England for 2003-2005. The Annual Survey of Hours and Earnings (ASHE) is used to compute the SSWDs. This is a large national data-set based on $1 \%$ sample of employees identified through the U.K’s Government (Pay as you Earn) tax system. This data is pooled over the three years to ensure the most precise estimates and reduce any year on year volatility. Vacancy rates were constructed as our measure of shortage of staff. This combines data on staffing levels with vacancy counts for positions which had been advertised for more than 3 months. This data was provided by the Department of Health and is at hospital trust level. There are 209 hospital trusts (an administrative unit comprising of one or more hospital sites providing care to the local population) in each of the three years resulting in 627 observations.

The distribution of vacancy rates are presented in Table 1 . On average there is a 
vacancy rate of $1.2 \%$ for assistant nurses and $2.5 \%$ for registered nurses. More than half of the hospital trusts do not have any vacant posts for assistant nurses while for registered nurses this is only the case for $17 \%$ of hospital trusts.

Table 1: Vacancy rates distribution in hospitals, 2003-2005 (627 obs.)

\begin{tabular}{llllllll}
\hline Vacancy rates & Mean & SD & NB Null & P30 & P50 & P70 & P90 \\
\hline Assistant nurses & 0.012 & 0.028 & $53,27 \%$ & 0 & 0 & 0.007 & 0.036 \\
Registered nurses & 0.023 & 0.032 & $17,38 \%$ & 0.004 & 0.012 & 0.023 & 0.062 \\
\hline
\end{tabular}

\section{Empirical Specification}

\subsection{SSWDs}

The first stage in the empirical analysis is the construction of our measure of pay competiveness using the private-public pay gap. This is based on the estimation of SSWDs from four wage equations. Two represent the two public sector staff (AN, n= 2993 and $\mathrm{RN}, \mathrm{n}=10761$ ) and two represent their comparators in the private sector (AN comparator, $\mathrm{n}=11896$ and $\mathrm{RN}$ comparator, $\mathrm{n}=29041$ ) as in equation 2:

$$
l h_{i k}=\alpha+X^{\prime} \beta+\mu_{k}+\varepsilon_{i}
$$

where $l h_{i k}$ is the log of hourly earnings of individual $i$ who works in area $k$. The matrix $\mathrm{X}$ contains the standardizing variables (age, age-square, gender, year dummies and for the private sector only industry and occupational dummies), $\varepsilon_{i}$ are the individualspecific error terms and $\mu_{k}$ are the area-specific effects: the SSWDs. The SSWDs are estimated at Local Authority District Level. This is an administrative unit in the U.K. with over 300 areas defined in England at the period of our study. They are estimated using effects coding, applied to (1) and finally centred to create our two public-private pay gap measures for assistant and registered nurses. The process of centring means that 
a region with a positive AN (RN) two public-private pay gap has an AN (RN) SSWD relatively larger than the private sector compared to the national mean difference. Conversely, a negative public-private pay gap indicates an area where the AN (RN) SSWD is smaller relative to the private sector compared to the national mean difference. The value of the gap indicates by how much this difference is in percentage terms. For example, a gap of 0.1 for $\mathrm{RN}$ indicates that the standardised $\mathrm{RN}$ wage in the area is more competitive by approximately $10 \%$ compared to the national mean.

\subsection{Vacancy Model}

The model to be tested is the following:

$$
V A C A N C Y_{j}=\propto_{j}+\beta_{1} g a p_{k}^{A N}+\beta_{2} g a p_{k}^{R N}+X_{j}^{\prime} \gamma+\varepsilon_{j}
$$

where $\mathrm{VACANCY}_{\mathrm{j}}$ is the vacancy rate of hospital $j$ for assistant (registered) nurses and $\beta_{1}$ and $\beta_{2}$ are the parameters for $g a p_{k}^{A N}$ and $g a p_{k}^{R N}$ which are our constructed measures for the public-private pay gap of assistant and registered nurses for area $k$ and our main parameters of interest.

$\mathrm{X}$ is a matrix of control variables and includes size, type of hospital trust, number of hospitals in each trust and the trust's foundation status. The mean number of beds is around 700 beds per hospital with a standard deviation of more than 400 beds. The type of hospital trust was identified from Crilly et al. (2007), where trusts are distinguished as Specialist, Acute, Teaching, Mental Health or Other Trusts. Just over half of hospital trusts are classed as acute with around 5\% classed as Other (children or specialist such as orthopaedic hospitals). During the period an additional Foundation Trust (FT) status was rolled out. FTs were granted more freedom from central control including the ability to manage their own budgets. FT status was granted on a selection basis by the 
government based on financial and quality aspects of performance. Around 13\% of hospital trusts had or were about to be awarded FT status in the time period studied.

The distribution of the vacancy rates would suggest estimation of (3) by a Poisson zero inflated model. However after testing this specification against OLS we found similar marginal effect for all variables. We therefore present the simpler linear model estimated by Ordinary Least Squares. We estimate (3) with a modified variancecovariance matrix to take into account the repeated hospital trusts within the data-set. This provides cluster-robust standard errors (Arai 2011; Cameron and Miller 2010).

\section{Results}

Table 2 reports the summary results of our constructed measure of the public-private pay gap for assistant and registered nurses.

Table 2: Public-private pay gap

\begin{tabular}{lllllllll}
\hline & N & Mean & sd & Min & Max & P10 & P50 & P90 \\
\hline Assistant Nurses gap & 627 & 0 & 0,123 & $-0,33$ & 0,4 & $-0,16$ & 0,003 & 0,127 \\
Registered Nurses gap & 627 & 0 & 0,111 & $-0,28$ & 0,245 & $-0,16$ & 0,007 & 0,129 \\
\hline
\end{tabular}

It is this measure that is included within the vacancy model (3) to test whether the pay gap is linked to the both shortage of own staff and if it impacts on other staff. The results for both assistant and registered nurses are reported in table 3. 
Table 3 Vacancy rate regressions for nursing staff

\begin{tabular}{|c|c|c|c|c|}
\hline & \multicolumn{2}{|c|}{ Assistant Nurses } & \multicolumn{2}{|c|}{ Registered Nurses } \\
\hline & $\begin{array}{l}\text { Estimate } \\
\text { (Std Err) }\end{array}$ & $P$ value & $\begin{array}{l}\text { Estimate } \\
\text { (Std Err) }\end{array}$ & P value \\
\hline Intercept & $\begin{array}{c}0.01 \\
(0.004)\end{array}$ & $0.011^{* *}$ & $\begin{array}{c}0.023 \\
(0.005)\end{array}$ & $<0.001 * * *$ \\
\hline Gap AN & $\begin{array}{c}-0.013 \\
(0.014)\end{array}$ & 0.361 & $\begin{array}{c}0.005 \\
(0.018)\end{array}$ & 0.792 \\
\hline Gap RN & $\begin{array}{l}-0.044 \\
(0.02)\end{array}$ & $0.024 * *$ & $\begin{array}{c}-0.059 \\
(0.021)\end{array}$ & $0.006^{* * *}$ \\
\hline Number of Beds & $\begin{array}{c}0.001 \\
(<0.001)\end{array}$ & 0.862 & $\begin{array}{c}-0.001 \\
(<0.001)\end{array}$ & 0.866 \\
\hline $\mathrm{Nb}$ of hospitals & $\begin{array}{l}-0.001 \\
(0.001)\end{array}$ & 0.817 & $\begin{array}{l}-0.001 \\
(0.001)\end{array}$ & 0.994 \\
\hline Foundation Trust & $\begin{array}{l}-0.003 \\
(0.003)\end{array}$ & 0.223 & $\begin{array}{c}-0.007 \\
(0.004)\end{array}$ & $0.068^{*}$ \\
\hline Mental & $\begin{array}{c}0.011 \\
(0.008)\end{array}$ & 0.197 & $\begin{array}{c}0.006 \\
(0.008)\end{array}$ & 0.449 \\
\hline Teaching & $\begin{array}{c}0.001 \\
(0.006)\end{array}$ & 0.872 & $\begin{array}{c}0.002 \\
(0.006)\end{array}$ & 0.768 \\
\hline Other & $\begin{array}{c}0.008 \\
(0.014)\end{array}$ & 0.561 & $\begin{array}{c}0.009 \\
(0.016)\end{array}$ & 0.564 \\
\hline Specialist & $\begin{array}{c}0.001 \\
(0.006) \\
\end{array}$ & 0.832 & $\begin{array}{c}0.005 \\
(0.011) \\
\end{array}$ & 0.667 \\
\hline $\begin{array}{l}\text { Number of } \\
\text { Observations }\end{array}$ & & & & \\
\hline $\begin{array}{l}\text { Adjusted R } \\
\text { Square }\end{array}$ & & & & \\
\hline
\end{tabular}

$* * * \mathrm{p}<0.01, * * \mathrm{p}<0.05, * \mathrm{p}<0.1$.

There is no evidence that the type of hospital trust has any impact on the vacancy rates of staff. Neither is there evidence that the number of beds is associated with vacancy rates. Hospital trusts with foundation status have a lower vacancy rate for registered nurses. However, our focus of attention is the public-private pay gap measures. The results indicate that the registered nurse vacancy rate is associated with registered 
nurses pay competitiveness as measured by the RN public-private pay gap measure. There are lower vacancy rates in hospital trusts for which the registered nurses pay is more competitive. This is consistent with Elliott (2007; 2010).

There is no effect of the assistant nurse public-private pay gap on the shortage of assistant nurses. However, the vacancy rate of assistant nurses is negatively associated with the registered nurses pay gap. A more competitive registered nurses pay increases the supply of assistant nurses. Areas where pay for registered nurses is more competitive by $10 \%$ compared to the national mean, decreases the registered nurses vacancy rates by $0.59 \%$ and decreases the assistant nurses vacancy rates by $0.44 \%$. Effects are therefore around $15 \%$ and $18 \%$ of the standard deviation for assistant nurse vacancy rates and registered nurse vacancy rates respectively. There is no evidence that the pay competitiveness of assistant nurses impacts on the vacancy rate of registered nurses.

\section{Discussion and conclusion}

This paper tests for the impact of local pay competitiveness on nurse staff shortages using a measure of the public-private pay gap of assistant and registered nurses. Where hospitals cannot adjust the rate of pay to reflect local labour market conditions, they may face difficulties to attract and retain staff. In particular, we allow for interactions between these two types of nurses and test for both the effect of the public-private pay gap for assistant nurses on the shortage of registered nurses and vice-versa.

We find no evidence that the pay competiveness of assistant nurses influences their own vacancy rate. This might be considered surprising as we might expect that with low levels of specialised skills, assistant nurses may be able to directly transfer to private sector occupations offering more competitive pay. However, the absence of such an 
effect may reflect other rewards such as stability of stability of employment and pension schemes that the public sector offers and this may be relatively more important for lower educated workers (Van de Walle et al 2015).

Our results confirm previous findings that the registered nurses pay competitiveness drives down vacancies of registered nurses. In addition, registered nurses pay competitiveness also drives down vacancies of assistant nurses. Assistant nurses are more easily recruited in hospitals with more competitive registered nurses pay. This link may relate to skill-mix and task substitution between the two types of nurse. Task delegation from registered to assistant nurses is widely performed in hospitals within the UK (Cavendish 2013). Where there are difficulties in hiring registered nurses, more may be expected from the assistant nurses on the ward and this may affect their recruitment and retention. While there is much written in terms of the impact of staff workload on issues such as nurse burnout and intentions to quit relating to registered nurse behaviour (Kutney-Lee (2013), Aiken et al (2012)), there is less written on assistant nurses. Lacher et al (2015) consider the impact of the working environment on the behaviour of healthcare assistants who provide support to registered nurses within the Swiss healthcare system. They found a negative association between a self-reported working environment measure (that included staffing and resource adequacy as one of five elements) and measures of burnout and intentions to quit.

A second link between the two nurse types may be through career-ladders. If the position of assistant nurse is regarded as a bridge to the more qualified registered nurse, then the attractiveness of the registered nurse position may influence the shortage of the entry-stage assistant nurse position. However, there is no published evidence as to how many assistant nurses do transition to fully registered nurse in the UK and as such this link is more conjecture. There is some past evidence that suggests hospitals did support 
such career-ladders through secondments to training (Grimshaw 2009). More recently, the role of assistant nurse as a potential entry point to full registered status has been recognised in Switzerland. Trede and Scherwi (2013) find evidence that the intentions of assistant nurses to progress to registered nurse is indeed influenced by future incomes. Interestingly within the U.K. a new role of associate nurse has been recently developed which includes a "pathway" to allow progression to registered nurse status.

It should be noted that while the results of this paper indicate recruitment of assistant nurses may be easier in areas where registered nurse pay is competitive, evidence suggests care must be taken in substituting one group for the other. Research that specifically looks at the skill-mix of registered and assistant nurse finds that substituting assistant nurses for registered nurses may impact negatively on patient outcomes (see Aiken et al 2014, 2017, Griffiths et al 2016).

Finding evidence that cross correlations of the competitiveness of pay exist between nursing staff groups implies that further research should investigate if they exist elsewhere in the healthcare sector. One extension is to link the pay competitiveness of nursing staff with the vacancy rates of doctors and vice versa. If the public-private sector pay gaps captures hidden characteristics of the workplace, finding for instance an impact of doctors pay competitiveness on the RN shortage, we would expect it to be the consequence of increase workloads, and vice-versa. This potential spill-over effect suggests that measures to tackle one occupational shortage may require consideration of the competitiveness of pay of other occupational groups.

A shortage of health care staff is recognised as a global problem against ever increasing demands on health services. As such it would seem beneficial to better understand the impact of the competitiveness of pay between the alternative occupational groups that 
make up the healthcare workforce. This could provide some insight into both the economic drivers and potential solutions in terms of pay reform to support the supply of the healthcare workforce.

Aiken LH, Sloane D, Griffiths P for the RN4CAST Consortium et al. (2017) "Nursing skill mix in European hospitals: cross-sectional study of the association with mortality, patient ratings, and quality of care” BMJ Quality Safety 26:559-568

Aiken LH, Sloane DM, Bruyneel L, et al. (2014) Nurse staffing and education and hospital mortality in nine European countries: a retrospective observational study. Lancet 2014;383:1824-30

Aiken LH, Sermeus W, Vanden Heede K, et al. Patient safety, satisfaction, and quality of hospital care: cross-sectional surveys of nurses and patients in 12 countries in Europe and the United States. BMJ 2012;344:e1717

Arai, Mahmood. 2011. “Cluster-Robust Standard Errors Using R.” Stockholm University. http://people.su.se/ ma/clustering.pdf.

Binley. 2004. Binley's Directory of NHS Management. Beechwood House Publishing. Cameron, A, and Douglas Miller. 2010. "Robust Inference with Clustered Data.” In Handbook of Empirical Economics and Finance, edited by Aman Ullah and David Giles, 20103666:1-28. Chapman and Hall/CRC. http://www.crcnetbase.com/doi/abs/10.1201/b10440-2.

Cavendish, Camilla. 2013. "Cavendish Review : An Independent Review into Healthcare Assistants and Support Workers in the NHS and Social Care Settings.” London, UK: Department of Health. https://www.gov.uk/government/uploads/system/uploads/attachment_data/file/2 36212/Cavendish_Review.pdf.

Crilly, Tessa, John Crilly, Margaret Conroy, Roy Carr-Hill, and David Parkin. 2007. "Review of Specific Cost Approach to Staff Market Forces Factor.” Department of Health.

Elliott, Robert Francis, Ada Ma, Anthony Scott, David Bell, and Elizabeth Roberts. 2007. "Geographically Differentiated Pay in the Labour Market for Nurses." Journal of Health Economics 26 (1):190-212.

Elliott, Robert Francis, Ada Ma, Matt Sutton, Diane Skatun, Nigel Rice, Stephen Morris, and Alex McConnachie. 2010. "The Role of the Staff MFF in Distributing NHS Funding: Taking Account of Differences in Local Labour Market Conditions.” Health Economics 19 (5):532-548. https://doi.org/10.1002/hec.1489.

Elliott, Robert Francis, Matt Sutton, Ada Ma, Alex McConnachie, Stephen Morris, Nigel Rice, and Diane Skåtun. 2006. "Reviewing the Market Factor Forces Formula.” London: Report to the Department of Health.

Griffiths, P., Ball, J., Murrells, T., Jones, S., and A.M. Rafferty (2016). "Registered Nurse, Healthcare Support Worker, Medical Staffing Levels and Mortality in Englsih Hospital Trusts: a Cross-sectional Study" BMJ Open 6:2 
Grimshaw, Damian. 2009. “Can More Inclusive Wage-Setting Institutions Improve Low-Wage Work? Pay Trends in the United Kingdom's Public-Sector Hospitals.” International Labour Review 148 (4).

Kutney-Lee A., Wu E.S., Sloane D.M., and LH. Aiken (2013) "Changes in hospital nurse work environments and nurse job outcomes: An analysis of panel data" International Journal of Nursing Studies 50:2:195-201

Lacher S, Geest S, Denhaerynck K, Trede I\& Ausserhofer D (2015) The quality of nurses' work environment and workforce outcomes from the perspective of swiss allied healthcare assistants and registered nurses: a cross-sectional survey. Journal of Nursing Scholarship 47, 458-467.

Metcalf, D., K. Hansen, and A. Charlwood. 2001. "Unions and the Sword of Justice: Unions and Pay Systems, Pay Inequality, Pay Discrimination and Low Pay.” National Institute Economic Review 176 (1):61-75. https://doi.org/10.1177/002795010117600106.

Office of National Statistics (2000) Standard Occupational Classification Volume 2

Rosen, Sherwin. 1986. “Chapter 12 The Theory of Equalizing Differences.” In , edited by Orley C. Ashenfelter and Richard Layard, Volume 1:641-92. Handbook of Labor Economics. Elsevier.

Smith, Adam. 1776. An Inquiry into the Nature and Causes of the Wealth of the Nations. London: W. Strahan and T. Cadell.

Traxler, Franz, and Bernd Brandl. 2011. "The Economic Impact of Collective Bargaining Coverage.” In The Role of Collective Bargaining in the Global Economy, edited by Susan Hayter. Cheltenham, UK and Northamption, MA, USA: Edward Elgar.

Van de Walle, Steven., Steeijn B., and Sebastian Jilke. 2015. "Extrinsic motivation, PSM and labour market characteristics: a multilevel model of public sector employment preference in 26 countries " International Review of Administrative Sciences 81 (4), pp833-855 